\title{
Self-Management in Daily Life with Psoriasis: An Integrative Review of Patient Needs for Structured Education
}

\author{
Gitte Susanne Rasmussen, ${ }^{1}$ Helle Terkildsen Maindal, ${ }^{2}$ and Kirsten Lomborg ${ }^{2}$ \\ ${ }^{1}$ Department of Dermatology, Aarhus University Hospital, 8000 Aarhus, Denmark \\ ${ }^{2}$ Department of Public Health, Aarhus University, 8000 Aarhus, Denmark
}

Correspondence should be addressed to Gitte Susanne Rasmussen, gittramu@rm.dk

Received 10 July 2012; Revised 26 September 2012; Accepted 10 October 2012

Academic Editor: Patricia M. Davidson

Copyright ( 2012 Gitte Susanne Rasmussen et al. This is an open access article distributed under the Creative Commons Attribution License, which permits unrestricted use, distribution, and reproduction in any medium, provided the original work is properly cited.

\begin{abstract}
The aim of this integrative review is to identify and discuss patient needs for education to support self-management in daily life with psoriasis. As psoriasis increasingly gains recognition as a serious chronic autoimmune skin disease with long-term impairment on the life course, and not mainly a cosmetic problem, nurses are highly challenged to develop efficient education to support patient self-management. The paper includes five stages: (1) problem identification, (2) literature search, (3) data evaluation, (4) data analysis and synthesis, and (5) presentation, based on theoretic scaffolding around the concept "need." Nineteen of 164 original papers within nursing, medicine and psychology, and reflecting patient perspective were included. To capture the patients' cultural understanding of the implications of the disease and care, we developed an interlevel model indicating that self-experienced burden of disease and its visibility, personal conditions such as illness perception, and the patient's age at onset time are high-impact factors that should be addressed in future structured patient education programmes. The research on patient needs has hitherto focused on adults, but the problems and vulnerability associated with having a chronic and visible disease during adolescence must be acknowledged, and patient education initiatives designed for this young group are recommended.
\end{abstract}

\section{Introduction}

Psoriasis is a common chronic inflammatory immune-mediated skin disease characterised by red, thickened, and scaly skin. Approximately 2 per cent of the world's population currently live with psoriasis, the prevalence appearing to be highest in Scandinavian countries and Northern Europe [1]. Recent research reports that the onset of the disease occurs before the age of 16 in $27-45 \%$ of the cases and before the age of 20 in more than $50 \%$ of the cases $[2,3]$. The course of disease varies greatly, and treatment is often time-consuming and distressing [4].

The growing interest in psoriasis has underlined that the disease constitutes a substantial physical burden and may impact the patient's life course in various ways. Numerous studies in the field of Health-Related Quality of Life have quantified the impact of psoriasis on daily functions and activities [5-8] as well as quality of life to an extent similar to other major diseases such as cancer, diabetes, and cardiovascular disease [9]. It is commonly recognised that the stigma associated with visible skin lesions may lead to psychosocial adjustment problems $[10,11]$.

Psoriasis is not only a cosmetic problem for the patients. A recent review has reported an association between psoriasis and severe physical conditions such as psoriatic arthritis, cardiovascular disease, metabolic syndrome, and Crohn's disease. In addition, life expectancy is reduced by several years in individuals with severe disease, mainly caused by increased risk of heart disease [12].

This new insight has resulted in an upcoming shift in the treatment of psoriasis, from exclusively treating a skin disease towards comprehensive disease management including early diagnosing, monitoring, and intervention. This shift has increased the focus on developing new interventions, and patient education is one of several initiatives that aim to motivate people to chronic disease self-management. Selfmanagement is generally defined as the day-to-day activity 
that an individual carries out to manage his/her long-term health condition. There is no gold standard definition of selfmanagement within nursing science. The on-going discussion to clarify and develop this concept [13-18] emphasizes that self-management can be viewed from three perspectives: a process reflecting the patients perspective; a structure that reflects the perspective of the health professionals often described as educational activities; and a goal or an outcome for the patient, for example, to improve quality of life or maintain health or well-being. In accordance with the aim of this review it seems relevant to adopt the patient's perspective on the concept of self-management. The concept refers to the activities people undertake to create order, discipline and control in their lives. Self-management is an active and dynamic process of learning, trying and exploring the boundaries created by illness, and it fluctuates as life and illness itself presents new challenges ([15], page 265) .

Despite increasing emphasis on the need for structured disease-specific patient education programmes in severe chronic illness [19], only a few studies on patient education in the area of psoriasis are available [20-24]. The research in this area has tended to focus on the importance of the physician-patient relationship to improve the patients' perceived control of the disease $[20,22]$ as well as information on psoriasis and treatment as a way to improve adherence to treatment, skin care $[22,24]$ and psychological relief [23]. One disease management programme focused on knowledge of the disease, patient skills training and psychological support [24], documenting improvements on disease severity, adherence to treatment and quality of life. Although the inclusion of psychosocial aspects is recommended in structured education programmes $[5,25$, 26], one review [27] reported a lack of evidence of the effect of psychosocial interventions for individuals with visible differences including psoriasis.

With one exception, the above-mentioned studies reflect the health professionals' perspective of what is important in educations programmes. Less attention has been paid to the patients' perspective and substantial educational needs in daily life. Linder et al. [22] identified hope of curability, perception of control and understanding from the physicians as valuable elements for the patients. Generally, the studies provide no clear recommendations related to content, pedagogical considerations, patient involvement, or outcome measures.

In nursing science, Thorne et al. have shown that patients depict a specific "world of disease" for each chronic diseasea cultural knowledge of the implications of the illness and the particular care for that world $[19,28]$. This cultural knowledge greatly influences how information about the disease and health is received by patients and consequently should be taken into consideration when developing patient education. A similar viewpoint is reflected in a recent Danish Health Technology Assessment (HTA) about patient education [19]. The HTA recommends that the patients' experience of the specific nature, characteristics, and course of disease should be involved when developing new interventions. This means that a new intervention should focus on the needs of the patient, thereby ensuring patient-oriented criteria for success as an important factor determining the content of the programmes.

To our knowledge, no studies have yet investigated the needs assessments related to patients with psoriasis. According to Bartholomew et al. [29], the initial process of needs assessment may include a systematic study of the scientific literature reporting on the discrepancy between what is and what should be, experienced by patients living with a problem like psoriasis. This discrepancy should be studied in relation to quality of life, health status, and factors that influence health and health risk. These factors include lifestyle, health behaviour and social behaviour, personal factors like self-care, coping and adaption as well as family as part of the environmental factors.

Therefore, we designed an integrative review to gain insight into and achieve a comprehensive understanding of people living with psoriasis and their needs for patient education based on their perspectives. The review aimed to answer the question: which factors related to the disease and the course of disease may, according to the existing literature, impact patients' needs of structured patient education to support self-management of psoriasis in daily life?

\section{Methods and Materials}

An integrative review of the literature was conducted, applying the strategy for this method described by Whittemore and Knafl $[30,31]$. The method was chosen because qualitative and quantitative studies can be combined within different disciplines. Consistent with this approach, the review included (1) problem identification (stated previously), (2) literature search, (3) data evaluation, (4) data analysis and synthesis, and (5) presentation.

2.1. Literature Search. A search strategy was designed in cooperation with a research librarian. Searches were conducted in February 2010 and repeated in January 2011. The following databases: Bibliotek.dk (Danish), PubMed, Embase, CINAHL, and SveMed+ were searched for papers in English or in a Scandinavian language published between 2000 and 2010/2011. A complementary search in PsycINFO was conducted in September 2012. Variants of the following keywords were searched separately and in combination, adapted to the thesaurus of the database concerned: psoriasis AND quality of life OR health status $O R$ lifestyle $O R$ health behaviour $O R$ social behaviour $O R$ family $O R$ self-care $O R$ coping $O R$ adaptation $A N D$ research $O R$ nursing research $O R$ interview $O R$ focus group $O R$ qualitative research $O R$ questionnaires $O R$ survey. Further references were searched for using reference lists in retrieved papers, and relevant nursing journals (Dermatology Nursing, Scandinavian Journal of Caring Science, Patient Education and Counselling, Chronic Illness) were checked to identify other relevant studies.

2.1.1. Selection Criteria. In addition to the main inclusion criteria mentioned above, further criteria were determined as they captured the focus of the research question. The papers should report on either the patients' perspective on 
the impact of psoriasis on their lives or their support needs to be able to manage the illness in everyday life. The papers were excluded if they (1) reported on medical treatment using quality of life measures as well as the development of measuring instruments, unless the patients' perspective of the impact of disease or self-management was clearly stated, (2) included several groups of patients unless the results for the psoriasis group were reported separately, or (3) reported separately on psoriasis arthritis, as arthritis has a different impact on function, fatigue, and pain than is the case with skin symptoms and therefore gives rise to different needs related to joint protection.

2.1.2. Data Evaluation. The titles and abstracts of all studies identified by the search strategies were assessed for their relevance to data extraction. Those that immediately met the inclusion criteria were selected for more detailed examination. The full-text versions of these studies were then obtained for close reading. The full-text reading caused the exclusion of papers that were not considered relevant to this study, for example, papers reporting on telephone consultancy methods or different models of illness and their suitability in medical practice, socioeconomic impact of disease, association between psychological variables and outpatient services. Due to the substantial diversity of the methodological approaches, we developed two quality criteria instruments according to recommendations by Polit and Beck [32] and Forsberg and Wengström [33] (see Table 1).

The instruments were developed for the qualitative and quantitative studies, respectively, enabling us to assess methods of research design, sampling, and conclusions. To prevent unnecessary complication of the analysis process, the quality of each included study was assessed as good or less good. Papers were included for final review if they generally met these criteria. A total of 770 papers were identified by key search terms, but most of these failed to meet all inclusion criteria (see Figure 1).

2.1.3. Data Analysis. According to the research strategy, each paper was carefully examined for data reduction, data display, data comparison, conclusion drawing, and verification [30]. The first phase of the data reduction classified the papers in terms of author, year of publication, country, research design, and disciplinary perspective. The disciplinary perspective was determined by the professional title of the first author and the name of his/her institution, and verified by web search if needed.

The second phase of the data reduction was performed according to aim, informants or population, data and measures, findings and results, and, finally, the authors' conclusion and discussion. For each paper, data relevant for the purpose of this study were extracted and organised in comparable frameworks. Thus, each primary source was reduced to a single page with similar data. Because of the fragmentation between the studies we found no heterogeneity of the above-mentioned variables, which is why an overall comparison of the studies would not make sense for the purpose of this study. We then proceeded inductively and developed a coding scheme where the objective of the coding is in the realm of themes and ideas [35]. In this approach, the objective of the coding is to develop a broad-based code, for example, physical symptoms from the skin in order to create collection of accounts, for example, pain, itching, scaling, discomfort, or not well at all, from which we could begin considering whether the phenomenon refers to illness, the trajectory, the treatment, the life phase, and so forth. The coding included 13 themes of significance to patient needs (see Table 3). The themes were divided into three separate clusters, and each paper was examined with the purpose of verification of coherence with the clusters (see Table 3.) To establish a clear connection between the clusters, each of the three clusters was further explored using the original data material to identify differences, similarities, and internal relationships. This in-depth analysis was synthesised into an interlevel model ([36] page 146) with the intention to present the complex interaction of high impact factors at different (psychological, social, and biological) levels related to the disease and course of the disease that should be addressed in future structured patient education programmes in order to support the patient' self-management in daily life.

\section{Findings}

Nineteen papers were included for final review, representing different countries: Norway, UK, Poland, The Netherlands, USA, Sweden, South Africa, Australia, and three disciplines: medicine, psychology, and nursing. Seven papers represented qualitative studies, while 12 papers represented quantitative studies. All selected papers address, in different ways, the patients' experience of discrepancy between how life is lived with psoriasis and how life should be lived. The purpose of the studies fall into two main groups: (1) to investigate the perspective of patients and/or families/partners on the impact or the burden of disease, and (2) to investigate the association between several different factors that influence the patients' ability to manage the disease in relation to function, well-being, and quality of life.

Different theories were applied in the studies, including Lazarus' \& Folkmann's coping theory, Leventhal's commonsense model as well as various theories on pain, self-concept, stigma, illness acceptance, and body phenomenology. A wide selection of measuring instruments were used, with Psoriasis Area and Severity Index (PASI) and Psoriasis Disability Index (PDI) being the most recurrent.

Three main clusters of high-impact factors were (1) disease-specific factors constituted by visibility of disease, onset time and the fluctuating nature of disease; (2) selfexperienced burden of disease, where the physiological, psychological, and social self-experienced burden of disease were the most frequent themes in most studies; (3) personal factors with themes like illness perception, coping strategy, gender, age, family, and partners. Table 3 shows the distribution of the selected studies on the three clusters (numbers indicate reference number in this paper). Several studies appear in more than one cluster. 
TABLE 1: Criteria for assessment of identified papers.

\begin{tabular}{|c|c|}
\hline Qualitative papers & Quantitative papers \\
\hline Problem stated unambiguously? & Statement of the problem? \\
\hline Ethical problems reflected? & Identified aim, hypothesis or research question? \\
\hline $\begin{array}{l}\text { Identified aims congruent with methodology and methods for } \\
\text { data collection and analysis? }\end{array}$ & $\begin{array}{l}\text { Sufficient description of the population and transferability into } \\
\text { Danish context? }\end{array}$ \\
\hline Sufficient details of the informants and settings? & Adequate description of measures? \\
\hline Method for data collection described? & Adequate description of data collection? \\
\hline $\begin{array}{l}\text { Sufficient detail of the process of analysis provided to ensure } \\
\text { accordance with selected method? }\end{array}$ & Sufficient description of data analysis? \\
\hline Results presented systematically? & $\begin{array}{l}\text { Findings adequately summarised and answering research } \\
\text { question? }\end{array}$ \\
\hline $\begin{array}{l}\text { Conclusions reflect results from the study and relevance for } \\
\text { practicing nursing in a Danish context? }\end{array}$ & $\begin{array}{l}\text { Generalisability of the findings for Danish nursing practice and } \\
\text { discipline? }\end{array}$ \\
\hline
\end{tabular}

\begin{tabular}{l}
\hline Subject headings and combinations: \\
Psoriasis \\
and \\
quality of life or health status or lifestyle or health behaviour or social behaviour or \\
family or self-care or coping or adaptation \\
and \\
research or nursing research or interview or focus group or qualitative research or \\
questionnaires or survey. \\
Limits: 2000-2010/2011. English or Scandinavian languages. Peer-reviewed journals. \\
Databases: PubMed (441), CINAHL (144), Embase (77), SweMed+ (28), PsycINFO (80), \\
Bibliotek.dk (0).
\end{tabular}
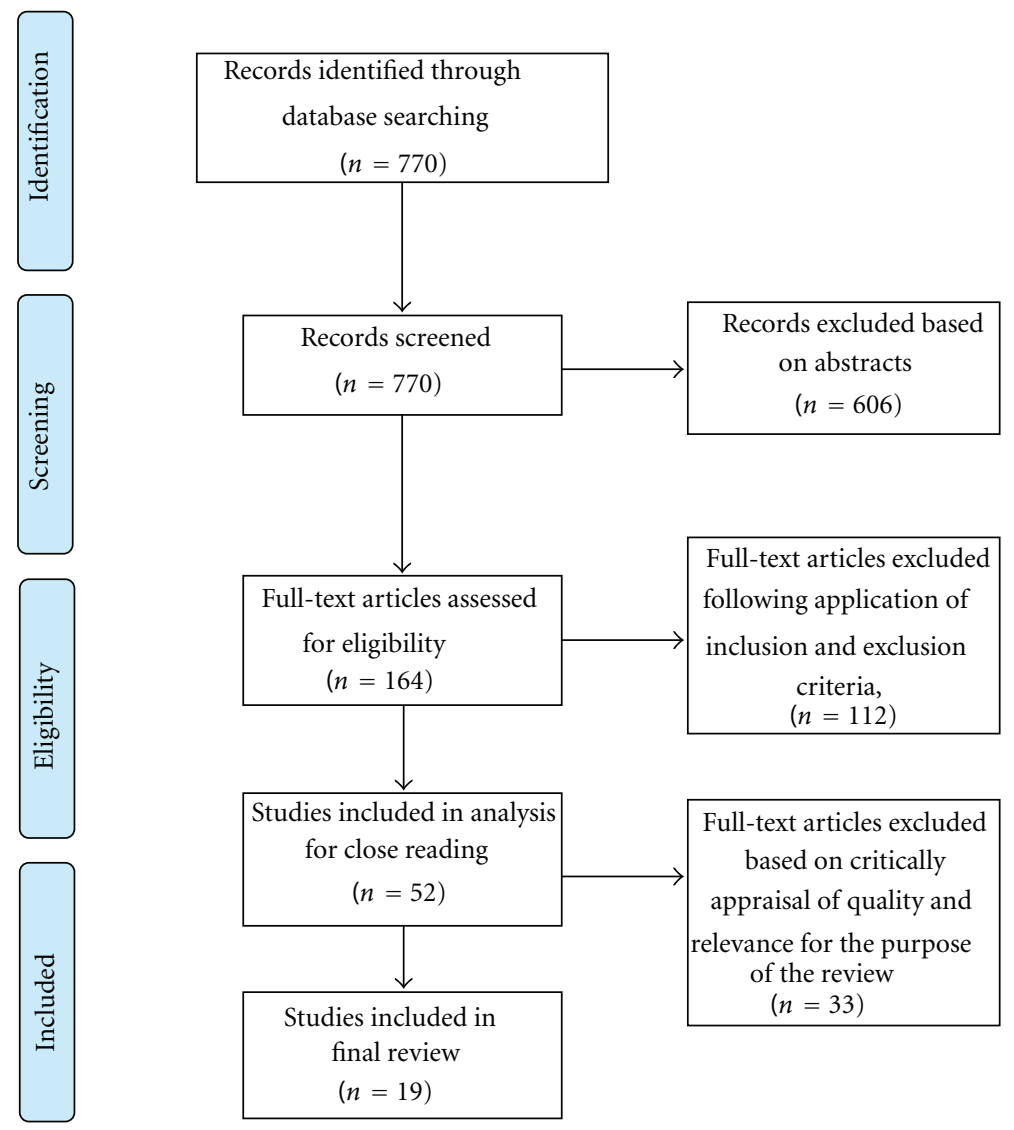

Figure 1: Flow diagram of the search process, adapted from Moher et al. [34]. 







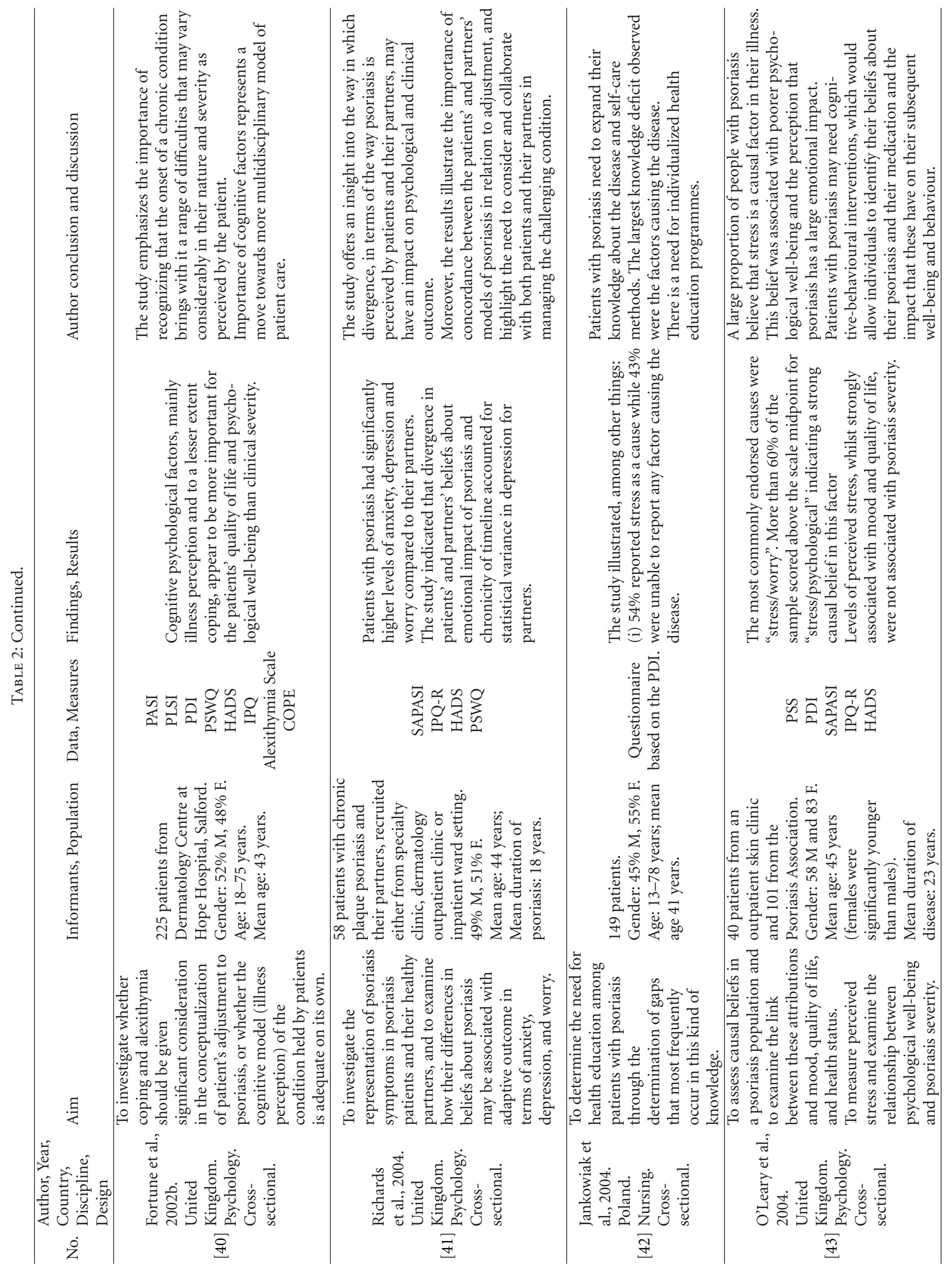




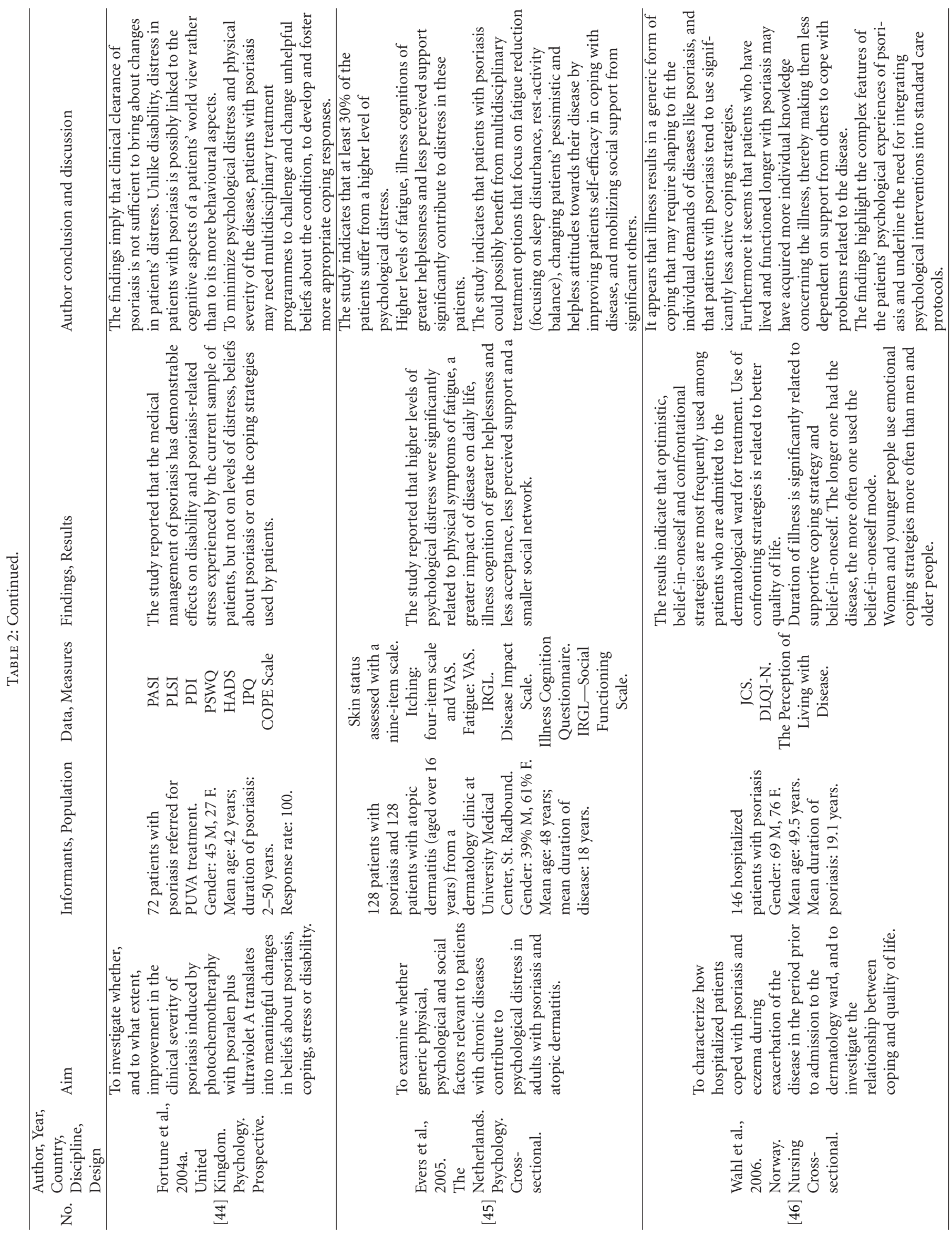




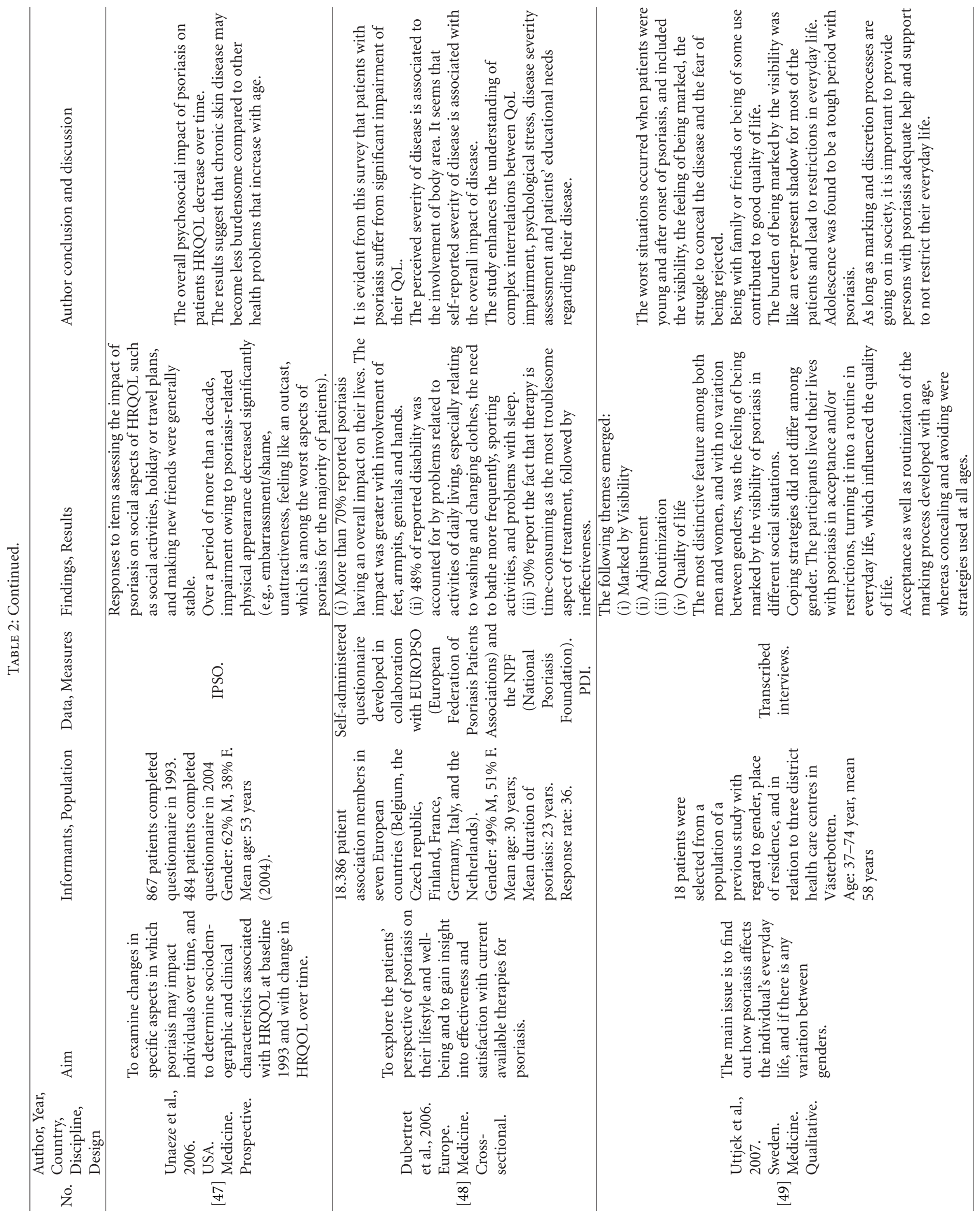




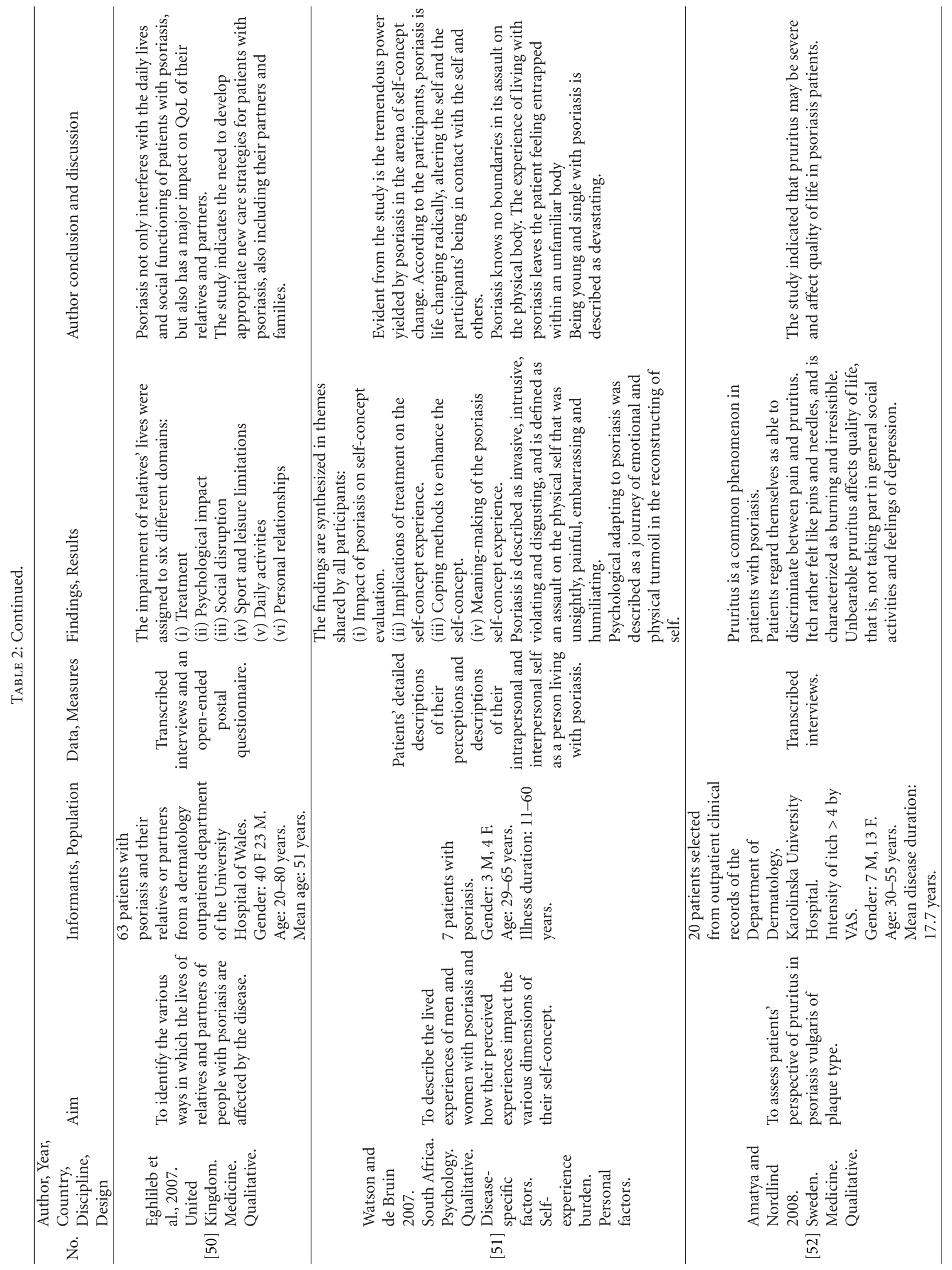




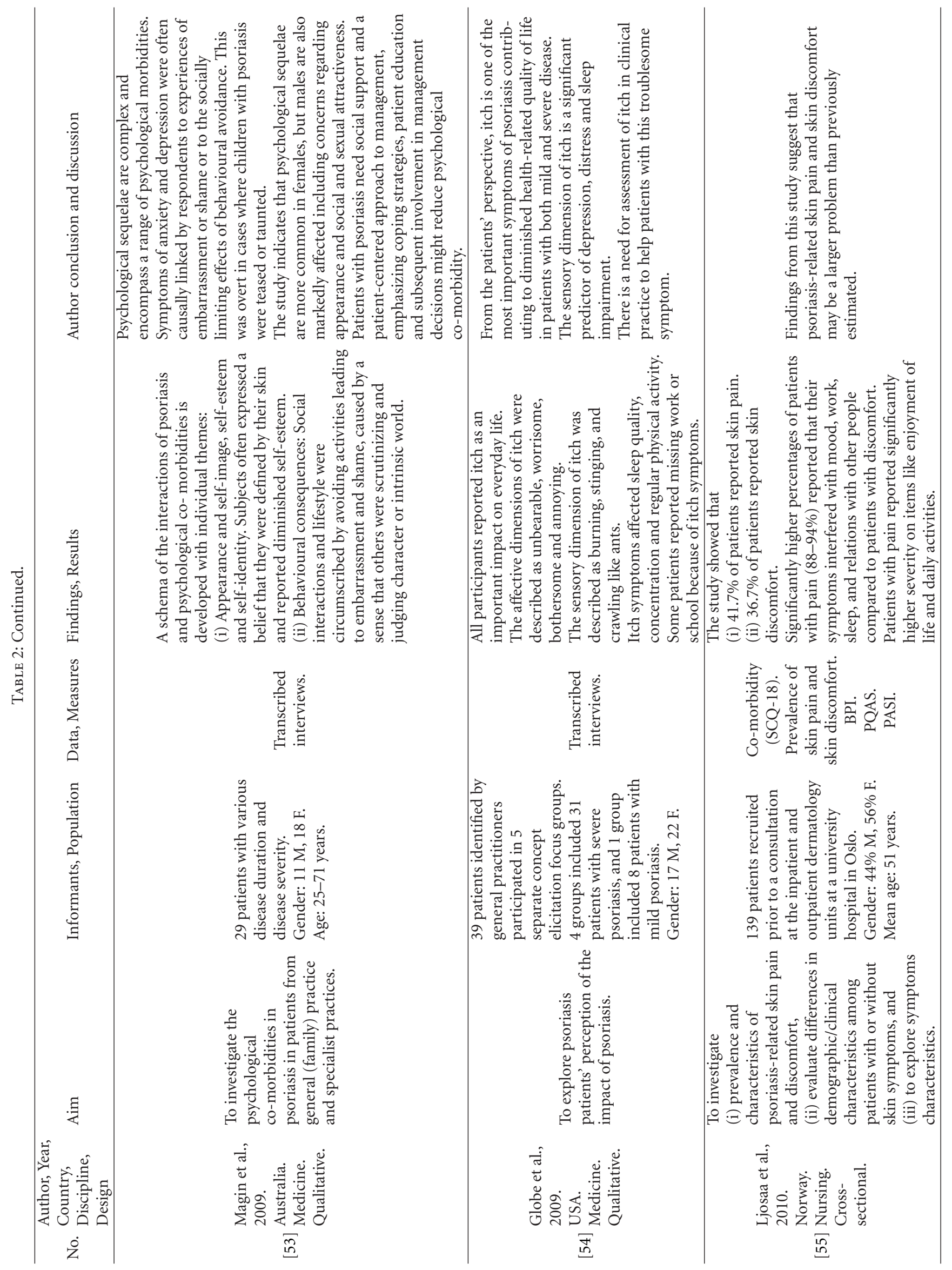


TABLE 3: Themes, clusters and verification of findings.

\begin{tabular}{lll}
\hline Theme & Cluster & Verification \\
\hline Visibility of disease & Disease-specific factors & {$[37,38,45,47-49,51-54]$} \\
$\begin{array}{l}\text { Onset time } \\
\text { Fluctuating nature of disease }\end{array}$ & & \\
$\begin{array}{l}\text { Physical symptoms: itch, pain, discomfort } \\
\text { Bodily suffering }\end{array}$ & Self-experienced burden of disease (physical) & \\
$\begin{array}{l}\text { Disease impact on self-concept } \\
\text { Psychological impact of disease }\end{array}$ & Self-experienced burden of disease (psychological) & {$[37,38,40,41,44,45,47-55]$} \\
$\begin{array}{l}\text { Disease as a psychological burden } \\
\text { Disease impact on family and partner }\end{array}$ & Self-experienced burden of disease (social) \\
$\begin{array}{l}\text { Disease impact on daily life } \\
\text { Personal coping strategies }\end{array}$ & \\
$\begin{array}{l}\text { Personal factors, illness perception } \\
\text { Personal factors, partner, family and network }\end{array}$ & Personal factors & {$[37-46,49,51,53]$} \\
\hline
\end{tabular}

\subsection{Disease-Specific Factors}

3.1.1. Visibility of the Disease. Visibility is distinctive for the nature of the disease and significantly influences how patients manage their disease. In a trans-European study, $48 \%$ of the patients reported that their quality of life was affected in relation to physical appearance [48]. For both men and women, the greatest difficulty of living with psoriasis was the sense of being marked by the disease $[38,49]$. Such experiences are described as a sense that other people tend to scrutinize and judge them, their character and inner world according to the appearance of their skin [53], or more correctly their own perception of this appearance [38]. In particular, the patients are worried that they may be perceived as having low hygienic standards, or that the disease is contagious [53]. This perception is especially distinct in patients who have experienced teasing and bullying during childhood $[49,53]$. The sense of being marked by the visibility of their disease was like an everpresent shadow for the majority of the patients, especially in out-groups and public places [49]. Visibility emerges as a general theme throughout the material to such an extent that it appears in all three clusters.

3.1.2. The Fluctuating Nature of the Disease. The disease is characterized by its fluctuating nature and thereby a fluctuating course of disease/trajectory. Patients experience their disease as a physical, tumultuous journey while the disease expands and one flare-up is followed by another [51], or as an eternal cycle where the patient at one time can function normally and the next moment finds himself almost isolated from the world. A symptom-free period can be experienced like being released from prison [38]. This fluctuating course of disease means that, when an accumulated loss of earlier self-perception cannot be restored and replaced by a new image, the patients may come to experience reduced self-esteem and self-confidence [38, 51].

3.1.3. The Significance of Onset Time. A number of studies suggest that the patient's age at onset time for the disease is perhaps the one factor with the greatest influence on the course of the disease $[49,53]$. This is probably linked up with the fact that the process of being marked begins very early. The sense of being young and single and suffering from an "ugly" disease like psoriasis is described as devastating. When they looked back, the patients related that, in their youth, they looked on their body with disgust and assumed that nobody would ever wish to be their partner [51].

One study points out that, in addition, the time immediately following onset is a significant factor for the course of disease [51]. This period can be filled with the fear of having to live with the disease and for the ensuing consequences. The understanding of the chronic nature of the disease and that one cannot be cured, either by one's own effort or with the help of others, is described as very depressing. These worries were felt most strongly by patients below the age of 30 and were expressed as thoughts of having no partner, job or close friend to rely on [49].

The studies show that fundamental conditions such as the visibility and fluctuating nature of the disease are of crucial importance to patients, not least if the onset occurs during adolescence.

3.2. Self-Experienced Burden of Disease. Patients with psoriasis suffer considerably from the impact of the disease on daily life as regards general health-related quality of life, disease-specific quality of life as well as quality of life as lived experience [37, 47-49]. In a Norwegian study, the patients reported a reduced general health-related quality of life within all of eight conceptual domains including: self-reported general health, physical functioning, bodily pain, mental health, physical role limitations, emotional role limitations, vitality, and social functioning [37]. Among European patient association members, 70 per cent of the respondents stated that the disease generally impacted their lives [48]. One study shows that patients, even after having lived many years with the disease, experience that psoriasis impacts their daily lives [49]. The studies distinctly indicate that the clinical severity of the disease has no causal relation to how patients experience the burden of their disease and 
the impact on their quality of life. It is the self-experienced severity of symptoms and outbreaks that constitute a key factor in relation to the course of disease and are significant for how well patients manage to live with their disease $[37,48]$.

3.2.1. Physical Burden of Disease: Itch, Pain, and Discomfort. Research in this field has mainly been focusing on patient perspective on the psychosocial burden of psoriasis rather than on how physical symptoms affect daily life. However, a frequently cited study on patients suffering from severe disease indicates that the disease is associated with an extensive experience of bodily suffering, physically described as pain and reduced mobility [38]. Recent studies indicate that the physical burden represented by itch $[52,54]$ as well as skin pain and discomfort [55] is likely to be more serious than has previously been assumed in cases of severe and mild disease.

In particular, several studies report itch to be one of the most unpleasant and irksome symptoms related to psoriasis. Itch is described as unbearable, worrisome, bothersome, and annoying, and the sensory dimension is described as burning, stinging, and crawling [54]. The sensory experience may be severe and may affect power of concentration, daily activity, physical activity, sexual activity, and sleep [52, 54]. One of the studies accentuate the need for the development of instruments that are capable of measuring itch in clinical practice, in order to better help the patient group manage this severe problem initially by acknowledging the problem itself [54].

The treatment as such is reported as bothersome and ineffective [48] and is experienced as unpleasant, painful, and draining the patients of time and energy. This applies to daily home treatment, hospital or clinic treatment as well as side effects such as itch, pain, smell, and cosmetic inconveniences. The patients describe a balance between treatment or no treatment of the skin and a feeling of being caught within the paradox of being damned if they treat the psoriasis, and being damned if they do not $[38,51]$.

\subsubsection{Psychological Burden of Disease: Change of Self-Concept.} A number of studies state that patients with psoriasis suffer from an increased level of anxiety and depression [37, 40, $44,48]$. The findings of these cross-sectional studies leave no doubt that the disease results in psychological implications. However, these findings are based on measurements developed chiefly for psychiatric diagnosing, and the study designs are not suited for unearthing causal connections and slight nuances in patient perception. In an Australian study, the patients' descriptions of their experiences of depression and anxiety did not reflect the symptoms as signs of clearly defined psychiatric diagnoses but rather as causally connected with experience of shyness, shamefulness, or social limitation related to the localization and visibility of the disease [53].

Likewise, studies investigating the lived experiences of the patients report that causal connections are complicated when trying to understand the psychological implications of the disease. The bodily changes caused by the disease and the degree of visibility may result in a changed self-concept. Patients experience that psoriasis has no boundaries in its assault on the physical body and perceive the disease as an enemy attacking the physical self [51]. They describe their bodies as being offensive, unclean, infectious, disgusting, leprous, ugly, unattractive, strange, or different [38]. The attack on the body is experienced as ungraceful, embarrassing, and humiliating, which may result in a feeling of helplessness and powerlessness, especially when not knowing the causes and implications of the disease or their possibilities for getting help or solace. It is concluded that psoriasis may be radically life-changing for the individual's relation to him-/herself and others, thereby resulting in deconstruction and selffragmentation [51].

This changed self-image has a considerable variety of feelings attached to it. Such feelings may be despair, melancholy, aggression and vulnerability [51], depression and anxiety $[41,45,53]$ as well as shamefulness. The highest emotional burden was found in women, but also men were clearly affected by worries about visibility and experience of limitations in relation to social and sexual activities $[49,53]$.

\subsubsection{Social Burden of Disease: Change of Self-Concept Results} in Social Vulnerability. Several studies report that the disease considerably influences the social functioning of the patient group $[37,47]$. This includes the impact on aspects related to holidays, travelling and making new friends [45], leisure activities such as sports and gymnastics, jobs and school attendance [48] as well as beauty care and cultural events [53].

Self-concept in interaction with reactions in the patient's surroundings and the patient's interpretation of such reactions may lead to social vulnerability. The patients transform their own thoughts and feelings about the look of their skin to other people and suffer from what they think other people think of them [38]. Most patients have the perception that their body no longer supports daily social activities.

Patients describe the fear of being rejected in social contexts as a considerable factor. The fear of being rejected is expressed as a strong wish to hide the disease, to make it nonvisible. Patients talk about respecting the rules of psoriasis in terms of diet and clothing [51]. The patients' struggle to conceal the disease is very time and energy consuming and may often result in considerable restrictions as regards lifestyle and daily activities. In particular, scaling is a nuisance to the patients in daily life, entailing the frequent changing of clothes, increased laundering and, not least, daily cleaning to remove scales from beds, floors, and chairs $[38,49,53]$.

A number of studies point out that the disease affects the entire family of the patient. The patients report that, during periods of disease activity, they experience themselves as a burden to their closest family [38]. A recent English study reports that many aspects of patient or family life may be affected. This primarily includes added house work in relation to skin treatment and removal of scales. Other aspects in this context were worry, social limitation due to 
embarrassment or the patient's need for help, leisure and holiday limitations as well as stressful relationships to the patient and other people. Finally, the informants pointed out impact on their sexual life [50].

To summarize, the analysis shows that the degree of selfexperienced severity and the assessment of the importance of the symptoms are crucial to how patients experience the burden of disease. The analysis shows that the disease may deeply influence daily life for the patients as well as their families/partners. Body perception and self-concept is changed in a way that increases the social vulnerability of the patient group. The fear of being rejected stands out as a considerable factor for planning and activities in daily life. The analysis also shows that in addition to visibility, itch, and skin pain are important in relation to how restrictions are perceived in everyday life.

3.3. Personal Factors. The included studies tend to point in two different directions: (1) one direction stipulating that knowledge of the patients' perception and interpretation of the disease is an important starting point, and (2) another direction emphasizing the knowledge of specific coping strategies of the patient group as a fundamental precondition for being able to help and support patients with psoriasis.

3.3.1. Illness Perception. Several studies state that illness perception is more important for how patients perceive functioning limitations than the extent and severity of the illness per se, and also state the existence of an association between illness perception and self-experienced psychological problems [40, 43-45]. Illness perception is constituted by the patient's perception of potential causes for the disease, experienced consequences of the disease, perception of or belief in recovery and control of the disease as well as disease identity.

One study showed that medical treatment of psoriasis affects physical functioning and perception of diseasespecific stress but does not affect the patients' worry, perception of the disease, or strategies for managing the disease. Even in cases of considerable improvement of the clinical severity of the disease, the patients' perception of psychological problems and coping strategies, for example, concealing, did not change [44]. This may be connected to the fact that worry and anxiety have been related to cognitive aspects such as illness perception rather than behavioural aspects such as coping strategies $[44,45]$.

Some studies show that more than 50 per cent of the respondents believe that personal causal connections such as stress may result in psoriasis and subsequent outbreaks $[42,43]$. Patients who believe that their disease is emotionally determined experience a considerably larger degree of morbid worry than patients who believe that their disease is determined by physical causes [44]. Stress as an assumed cause is associated with a low level of psychological wellbeing [43] and reduced knowledge of self-care actions [42]. An English study reported that inequality between the way patients and partners think about the disease may affect the psychological well-being of both parties as well as the clinical result [45].

3.3.2. Coping Strategies. Studies within nursing [46], psychology [39], and medicine [49] have investigated how patients cope with their disease in daily life. The studies are based on the coping theory developed by Lazarus and Folkmann as it offers a perspective that acknowledges the fact that patients develop coping strategies that interact with their environment. The studies presuppose that it is important to be able to understand the line of action taken by the patient in order to be able to provide support and care for the patient.

One study investigating general ways of coping with chronic medical conditions shows that patients with psoriasis did not apply coping strategies nearly as frequently as patients with chronic fatigue, atrial fibrillation, spinal cord injury, cancer, or myocardial infarction, especially with regard to social support [39]. This is interpreted as an indication that many of the problems experienced by the patients surpass the coping resources of the patient as well as his/her family and social network. Another study shows that having a family, a job or a close friend, being useful or feeling well were factors that facilitated coping and were able to make patients forget that they were suffering from psoriasis [49].

Results from a Norwegian study specifically investigating how individuals cope with severe exacerbation indicate that disease duration, age, and gender are important for the choice of strategy. Women and adolescents use emotional strategies more often than men and elderly people. Disease duration is important for how patients choose to act. The longer a person has lived with the disease, the more often a believe-in-yourself strategy is applied. The opposite is seen in relation to supporting strategies: the shorter the disease duration, the more often a supporting strategy is applied [46]. This indicates that individuals who had lived longer with psoriasis developed personalized knowledge about disease management that made them more independent of support to manage problems from other people. However, the findings from another study indicate that patients, irrespective of gender, choose the strategy that fits into their daily lives. In order to adjust themselves to the disease, the patients transformed the treatment and concealment strategies to everyday routines such as teeth brushing [49].

To summarize, the studies contribute to understanding that cognitive factors, such as illness perception and adequate choice of strategy to manage disease in daily life, have importance for the course of disease. However, patients with psoriasis do not apply coping strategies nearly as frequently as patients with other chronic diseases. The studies indicate that individuals with psoriasis tend to explain their disease based on personal causal connections, with a resulting negative impact on functioning and life quality. The studies also indicate that adolescents are in most need of support to manage their disease, while elderly patients and patients who have suffered from the disease for a long time develop a believe-in-yourself strategy and transform treatment and concealment strategies to everyday routines. 
3.4. Synthesis. The analysis indicated a number of highimpact factors that constitute the course of disease and consequently its influence on quality of life, function, and well-being for patients with psoriasis. A synthesis of the findings is shown in the interlevel model in Figure 2.

Figure 2 illustrates that course of disease is constituted through an interaction between various factors, grouped as disease-specific factors, self-experienced burden of disease, and personal (and environmental) factors. For each group, the model lists a selection of factors which, in their own right and in a complex interaction with other factors, influence on how well each patient manages his/her disease in everyday life and is able to achieve better functioning, well-being, and quality of life.

The data comparison demonstrated that visibility is a factor of radical importance to self-perception, social vulnerability, and daily activities in general. It is not the clinical extent of psoriasis, but rather the visibility-associated severity experienced by the patient that determines how severely the burden of disease is felt and which strategies the patient chooses for managing the disease. Furthermore, our analysis suggests a connection between the patient's perception of the disease and how the burden of disease is felt, and that this will influence how the patient chooses to act. The burden of disease is felt more profoundly if the patient's comprehension of what causes the disease is founded in a personal belief of cause and effect. The analysis also suggests that personal relationships with family and partner are significant with regard to social vulnerability and experienced burden of disease, and that quality of life for the patient and his/her partner is influenced by differences in perception of the disease.

The analysis of disease-specific factors suggests that the age at onset time and the time immediately following onset are significant determinants of successful self-management. Early onset influences the burden of disease and, seemingly, personal factors such as illness and body perception, while onset during adulthood does not result in the same degree of emotional strain. The fluctuating nature of the disease is a particular disease-specific factor. The self-experienced severity of the disease and the frequency of fluctuations of the disease seem to influence how well the patients will recover in each period between exacerbations, as well as the patient's self-perception and psychological problems.

\section{Discussion and Conclusion}

The findings from this integrative review of factors that may impact patients' needs of structured patient education reflect complexity, both in terms of the impact of the disease on the patients' health and quality of life and the specific cultural knowledge of this patient group. The model does not provide any answers as to how learning processes should be organised but contributes to the development of understanding and presentation of health problems in general in this patient group. Not least patients for whom it represents an excess burden, which in fact is the product of the first step in a needs assessment [29]. For this patient group in general, the most important lesson to be learned from this review is that patient needs must be understood in a complex interaction between self-experienced burden of disease and its visibility, personal conditions such as illness perception, and the patient's age at onset time. These factors appear to be of importance when considering the second phase of a needs assessment, where the connection between the needs and the programme outcomes is established [29], and within nursing, it is necessary to discuss the most appropriate methods and strategies to address the factors.

The experiences of being marked by the visibility of the disease was a finding we had anticipated, given that one in four patients experience significant psychological distress, and a perception of stigmatisation has been reported to be one of the most significant factors related to disability and quality of life [56]. However, the research on stigmatisation in this area has tended to focus on associations between various personal variables such as depression, age, gender and age of onset and to a lesser degree on the social processes reflected in our data. The findings indicate that an overly narrow focus on psychological implications may be problematic because it will always be attached to the individual. It has been discussed that if stigma is viewed as a personal property instead of a label attached by other people, this may have a decisive effect on where the responsibility is placed and, consequently, which interventions are applied [57]. This schism between, on the one hand, health professionals focusing on easing the patients' emotional reactions to their disease and, on the other hand, patients focusing on letting their experiences be expressed as routine actions with the purpose of hiding their disease seems to surface the tension that exists between what the health care system is offering and what patients think they need. Patient education interventions have often been organised in accordance with the needs of the clinician and the system taking priority in the delivery of patient care. In models like this, the professional is at the centre of the system, and the patient is expected to comply with the instructions given by the health care professional. If our findings are seen in a self-management perspective, they indicate that visibility can, with advantage, be understood in relation to how patients act on it as part of their struggle to create order and control in daily life.

In agreement with previous research within other chronic conditions [58] patients' causal beliefs of the illness and its consequences appear to be of greater importance for the patient group's health-related quality of life than the factual clinical severity of the illness. Worry and anxiety related to illness perception may limit the patients' choice of alternative points of view on themselves, their world, and their future. Nevertheless, illness perception must be emphasised as an important factor in relation to psoriasis patients, as in two of the studies 60 and 54 per cent of the patients, respectively, stated person-specific factors like stress as being the cause of their disease $[42,43,59]$. This is confirmed by a review [56] showing that $37-88$ per cent of the included patients stated stress as a disease cause. Recent stress research confirms that a majority of patients believe this to be true, but clearly states that stress cannot be established as a triggering factor in relation to psoriasis [56]. 


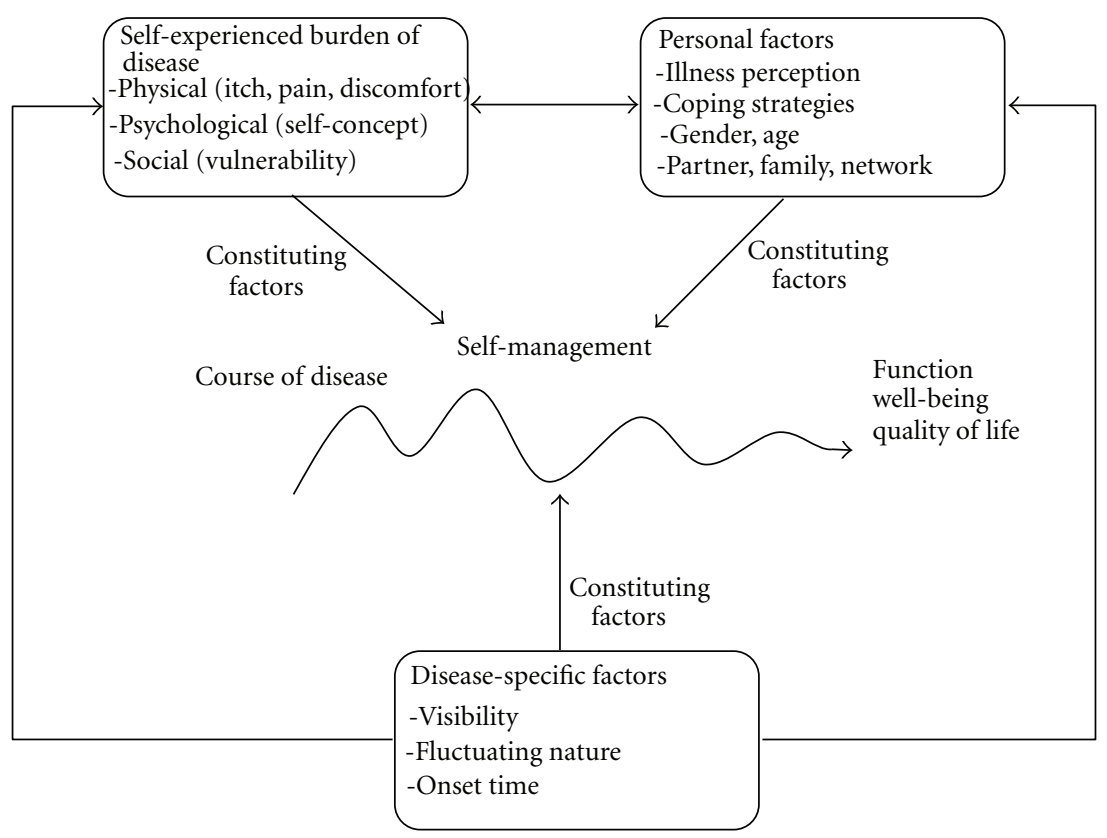

Figure 2: High-impact factors for patient self-management of psoriasis in daily life.

This discrepancy could be due to the fact that the disease has not, until recently, been recognised as an autoimmunemediated disease. For many years, it was a prevailing hypothesis that patients with psoriasis had a certain style of personality $[40,56]$. From this outset, health professionals have sought explanations for the disease in the patients' personal factors and stressful life events, and it has been suggested that health professionals may have contributed to creating this understanding [43]. For psoriasis patients, this understanding may have resulted in being particularly vulnerable to topics such as psychological condition and lifestyle, given a basic perception that they themselves are the reason for the onset and flare-ups of their disease. It is already known that patients with a disease of unknown causality are vulnerable to communication related to their psychological condition [28]. Historically, patients may have adapted the perception that no doubt has unconsciously been signalled by the health professions. Thus, the patients' illness perception is an important factor that should be taken into account when appraising the patient group's needs for patient education. Here lies a commitment to communicate the latest findings on disease causality if such knowledge prevents psychological difficulties.

The Danish Center for Health Technology Assessment [19] found that people with chronic diseases need diseasespecific knowledge and skills. Still, what is supposed to happen within the communication to steer the patients' course of disease is not at all well-known, and the HTA does not provide any comprehensive overviews of these needs. It is pointed out that the focus should be on the patients instead of the health care professionals' assumptions about the needs and the preferences of the patients. This means that the nursing discipline must critically discuss the customary way of defining clinical outcomes and the outcomes that are important for patients to live well with their disease. Thorne warns against the evaluation of interventions in terms of available indicators of treatment compliance and lifestyle control [60] and challenges nursing to adopt the perspective of expert patients; that there is no single way to live well with a chronic condition; that the learning process is complex and stepwise; and that the role of nursing science must be contextualised within an understanding of the living that is taking place [61].

There is emerging evidence that interventions that specifically aim to increase the patients' level of self-efficacy are more likely to produce positive outcomes in terms of behaviour change and health outcome. De Silva [62] for example, has reported that people with chronic conditions benefit from different outcomes like improvement of knowledge, technical skills, self-efficacy, and behaviour change. It may however be questioned whether these existing outcome measures really capture the benefits that are most important to the participants in the programmes. If this is not the case, many important factors can get left out when the impact of a programme is evaluated.

Our findings indicate that the outcomes must reflect the factors that may be important for the individual patient, both in spontaneous patient education and in planning for a more structured process. Outcomes must reflect how far the patient is in his or her course of the disease, how the burden of disease is experienced, how the body and illness is experienced, and the best ways for the patient to manage the disease. It seems that varied approaches are needed and that researchers in nursing science must build relationships with the patients and engage them in the research to map the outcomes which really benefit their lives. 
According to the theoretical concept behind needs assessment and health promotion intervention, "nothing is as useful as good theory" ([63] page 8). This means that when developing patient education programmes, the choice of a (multi-)theoretical framework contributes to a coherent intervention development addressing the content, the pedagogical methods, the organisational structures, the competency development of the health care professionals, and the development of outcome measures. However, based on the findings of this review it could be important to question whether these theoretically defined outcomes really meet actual patient needs.

Kennedy and Phillips argue for broader and more patient-centered measures to capture the social impact of patient education programmes [64]. They have shown that participating in a well-defined and evidence-based programmed as the Expert Patient Program [65] improved the participants' confidence, knowledge, and skills as a part of the programme curriculum, for example, improved diet, meeting new people, ability to control emotions, increased self-awareness, and increased self-worth. But these outcomes were not those valued most by the participants [64]. In focus group discussions with participants, the ancillary (not health-related) impact of the programme was mapped, and a general "theory of change" for this particular patient group was developed and tested. It seems that an increase in confidence leads to further outcomes such as decreased anxiety, better sleep, the ability to try new things, and increased motivation. Thus this method permits the mapping of variety of outcomes experienced by different participants, for example, improved relationships with family and friends, participating in volunteering initiatives, further education, or job-related outcomes.

Our findings indicate that when evaluating the patient group's general needs for patient education, the health care professionals must pay more attention to the various life phases where psoriasis sets in. This issue has not yet been focused on in a scientific context, and onset time is not an articulated theme in the included studies. The findings can be seen in the light of recent knowledge that the disease sets in either at an early age or relatively late in life. More than half of the patients experience onset before they reach 20, in most cases with the first symptoms appearing before the age of 16 . For the majority of the rest of the patient group, onset does not occur until the age of 50 to 60 . The group with early onset is characterised by a higher severity of the disease, while the group with late onset is characterised by lower illness severity $[2,66]$. Our data material is characterised by no inclusion of very young people in any of the studies. The average age for the included patients was between 40 and 52 years. Several studies included middle-aged patients with early onset, a fact that stands very clear in their memory. In the studies, the patients recounted in retrospect their fear of never being able to get a partner, a job, or a close friend, and that nobody would ever come to like them $[49,67]$. These stories illustrate that onset during adolescence was a great strain on them, and described as devastating. Our review indicates that patients with onset during adolescence had by far more difficulties with managing their daily life than patients with adult onset, especially with regard to psychological difficulties related to body and self-perception. One study found that psychological difficulties were particularly distinct in individuals who had experienced teasing or bullying as children or adolescents [53]. Research in young people with psoriasis is indeed limited, but a theoretical study indicates onset time to be a decisive factor for development of psychological difficulties [68]. In accordance with our findings, this study describes the onset of the disease in late childhood being experienced as a stranger and therefore a frightening experience. Patients in this developmental phase have a strong wish to understand what is happening to them. The study also points out that patients who do not get sufficient support to socialise with their contemporaries often tend to develop emotional problems and academic difficulties as adults. Findings from an online focus group survey [69] including young people between 11 and 18 showed that the young people struggle to make the disease fit into their lives. It is a struggle between "it" and "me", and the struggle is about controlling "it" and minimising its influence on their appearance and social functioning. Through the research process when articulating their experiences, the young people became aware that they were not alone in their struggle and were spontaneously practising peer support to help each other. The study argues that the resources achieved during adolescence are significant for the ensuing adult life phase. It seems likely that the potentially negative long-term effect of psoriasis may be reduced by participating in network groups during adolescence.

It appears that onset time is a high-impact factor that must be integrated in the planning of structured patient education programmes, taking into account that onset time is related to two very different age groups with different life phase challenges. In particular, it appears that we must increase our focus on the problems and the vulnerability related to having a visible disease such as psoriasis during childhood and adolescence and acknowledge the need for a preventive intervention at an early stage.

Overall, our findings indicate that further research is needed on the needs of patient education programmes. The research would benefit from the involvement of especially the young people in particular to explore their specific needs including specific and various outcomes relevant to their everyday life. When participants are involved in the designing process of patient education, they prioritise the educational content very differently from their teachers. Booker et al. [70] argue for development of educational interventions in cooperation with the patients using focus group discussions to articulate problems and outcomes. This is important both in relation to children and parents, as children need to understand what is happening to them, and in relation to adolescents during the critical period of developing their identity when they not only need family support but, to a greater extent, compare themselves with their contemporaries.

4.1. Study Limitations. This review has some limitations due to the complex method. On the one hand, the preliminary 
search of this review indicated limited research on nursing and nursing intervention within this patient group. On the other hand, the search revealed a widespread research reporting on the impact on quality of life, function, and well-being. The establishment of the theoretical scaffolding around "needs" ensured well-defined key words and improved the sensitivity of the search. This resulted in an extensive data material that enriched the understanding of patients' needs but challenged the selections and analytical process. Ideally, all relevant literature should be included in the review, and more studies might have been included to contribute to data saturation. However, a high degree of retrieval throughout the search process indicates that the review constitutes a representative picture of the available scientific knowledge on the phenomenon [32].

Given that the review is based on original studies from different disciplines and methodologies, there might be some limitations with regard to the data extraction. Although we have sought to be compliant with the research tradition, methods, concepts, and theories of the various disciplines, this complexity may have constituted a risk of misinterpreting the quality and the findings of some studies. However, we have put the interpretation of the existing knowledge into the context of current health care and into a theoretical understanding of the patients' perspective on self-management. This may contribute to the cumulative knowledge in nursing science and practice [71].

The review may also be confined due to the complexity of the data evaluation. Several of the primary sources contained weaknesses with regard to the selected quality criteria, but overall the quality was high. The studies that were valuated less good were to a lesser extent used in the analysis, for example, when the statement of the problem was not quite clear or the questionnaire was only partially validated.

It can be discussed whether our findings concerning the young people are transferable to present time, considering the relatively high average age and illness duration of the participants as the participants' experiences in most cases were formed in contexts more than a generation ago. It is questionable whether psychosocial difficulties experienced by the participants during adolescence would be similar today. We have found the difficulties to be transferable to present time, as body experience and self-representation during adolescence is more important than ever in Western countries.

The integrative review method is not different from other systematic review methods with regard to the fact that bias and errors may occur at any stage of the review process, and that attempting to eliminate all biases would be naïve. What is characteristic for this particular method is its ability to comprehend knowledge about a phenomenon in various disciplines and methodologies and the use of inductive analysis methods. This means that its foundation is not collection and comparison of evidence but an interpretation of existing knowledge. The aim of this analytic form extends beyond taking things apart and putting them back together again [35]. We present an interpretation that has the potential to contribute to present varied perspectives of the patients' needs and is thereby important to both nursing practice and nursing science. We have tried to ensure the validity and transferability of the interpretation by presenting the rather comprehensive (Table 2) that shows the data extraction of key data reported as thoroughly as possible, using the original language and expressions of the studies reviewed.

4.2. Conclusion. The aim of this integrative review has been to identify and describe patient needs for education to support self-management in daily life with psoriasis. We have identified a range of high-impact factors associated with the disease and its course that substantially influence the quality of life, functioning, and well-being of the patient group. These factors constitute, in mutual complex interaction, the course of disease and are significant with regard to how well the patient is able to manage his/her disease in everyday life. The factors are grouped into three clusters consisting of disease-specific factors, personal factors, and self-experienced burden of disease. We conclude that some of these factors may be particularly important to take into account when developing education programmes for this specific patient group. Among these factors are the patients' illness perception, how the visibility of the disease influences the psychological and social burden of the disease, and, not least, the particular importance of onset time, especially for the young patient group.

The study offers a profound understanding of what may be important to patients participating in self-management education, and the interlevel model offers a contribution to nursing practice to encourage nurses to involve patients in the development of new interventions.

\section{Authors' Contribution}

G. S. Rasmussen was involved in all phases of the study and of writing the paper. K. Lomborg was involved in deciding study design, drafting of paper, critical revision of important intellectual content, and supervision. H. T. Maindal was involved in critical revision of the paper.

\section{Conflict of Interests}

The authors declare that they no conflict of interests.

\section{References}

[1] A. Menter, C. Smith, and J. Barker, Fast Facts Psoriasis, Health Press Limited, Oxford, UK, 2004.

[2] S. P. Raychaudhuri and J. Gross, "A comparative study of pediatric onset psoriasis with adult onset psoriasis," Pediatric Dermatology, vol. 17, no. 3, pp. 174-178, 2000.

[3] S. Benoit and H. Hamm, "Childhood psoriasis," Clinics in Dermatology, vol. 25, no. 6, pp. 555-562, 2007.

[4] M. Kirkevold, "Toward a practice theory of caring for patients with chronic skin disease," Scholarly Inquiry for Nursing Practice, vol. 7, no. 1, pp. 37-53, 1993.

[5] A. Wahl, "The impact of psoriasis on psychosocial life domains: a review," Scandinavian Journal of Caring Sciences, vol. 11, no. 4, pp. 243-249, 1997. 
[6] R. Zachariae, C. Zachariae, H. Ibsen, J. Touborg Mortensen, and H. Christian Wulf, "Dermatology life quality index: data from Danish inpatients and outpatients," Acta DermatoVenereologica, vol. 80, no. 4, pp. 272-276, 2000.

[7] G. Krueger, J. Koo, M. Lebwohl, A. Menter, R. S. Stern, and T. Rolstad, "The impact of psoriasis on quality of life," Archives of Dermatology, vol. 137, no. 3, pp. 280-284, 2001.

[8] A. B. Kimball, C. Jacobson, S. Weiss, M. G. Vreeland, and Y. $\mathrm{Wu}$, "The psychosocial burden of psoriasis," American Journal of Clinical Dermatology, vol. 6, no. 6, pp. 383-392, 2005.

[9] S. R. Rapp, S. R. Feldamn, M. L. Exum et al., "Psoriasis causes as much disabilitiy as other medical diseases," Journal of the American Academy of Dermatology, vol. 41, pp. 401-407, 1999.

[10] I. H. Ginsburg and B. G. Link, "Psychosocial consequences of rejection and stigma feelings in psoriasis patients," International Journal of Dermatology, vol. 32, no. 8, pp. 587-591, 1993.

[11] M. A. Gupta, A. K. Gupta, and G. N. Watteel, "Perceived deprivation of social touch in psoriasis is associated with greater psychologic morbidity: an index of the stigma experience in dermatologic disorders," Cutis, vol. 61, no. 6, pp. 339-342, 1999.

[12] W. H. Boehncke, S. Boehncke, and M. P. Schön, "Managing comorbid disease in patients with psoriasis," British Medical Journal, vol. 340, Article ID b5666, 2010.

[13] J. Barlow, C. Wright, J. Sheasby, A. Turner, and J. Hainsworth, "Self-management approaches for people with chronic conditions: a review," Patient Education and Counseling, vol. 48, no. 2, pp. 177-187, 2002.

[14] L. S. Schilling, M. Grey, and K. A. Knafl, "The concept of selfmanagement of type 1 diabetes in children and adolescents: an evolutionary concept analysis," Journal of Advanced Nursing, vol. 37, no. 1, pp. 87-99, 2002.

[15] D. Kralik, T. Koch, K. Price, and N. Howard, "Chronic illness self-management: taking action to create order," Journal of Clinical Nursing, vol. 13, no. 2, pp. 259-267, 2004.

[16] P. M. Wilson, S. Kendall, and F. Brooks, "Nurses' responses to expert patients: the rhetoric and reality of self-management in long-term conditions: a grounded theory study," International Journal of Nursing Studies, vol. 43, no. 7, pp. 803-818, 2006.

[17] S. Coster and I. Norman, "Cochrane reviews of educational and self-management interventions to guide nursing practice: a review," International Journal of Nursing Studies, vol. 46, no. 4, pp. 508-528, 2009.

[18] M. Grey, K. Knafl, and R. McCorkle, "A framework for the study of self- and family management of chronic conditions," Nursing Outlook, vol. 54, no. 5, pp. 278-286, 2006.

[19] "Sundhedsstyrelsen, Monitorering \& Medicinsk Teknologivurdering. Patientuddannelse-en medicinsk teknologivurdering 2009," Medicinsk Teknologivurdering, vol. 11, no. 3, 2009.

[20] C. A. Lamb, R. G. Fried, and S. R. Feldman, "Giving patients "perceived control" over psoriasis: advice for optimizing the physician-patient relationship," Journal of Dermatological Treatment, vol. 15, no. 3, pp. 182-184, 2004.

[21] M. Skarpathiotakis, C. Fairlie, and S. Ryan, "Specialized education for patients with psoriasis: a patient survey on its value and effectiveness," Dermatology Nursing, vol. 18, no. 4, pp. 358-361, 2006.

[22] D. Linder, E. Dall'Olio, P. Gisondi et al., "Perception of disease and doctor-patient relationship experienced by patients with psoriasis: a questionnaire-based study," American Journal of Clinical Dermatology, vol. 10, no. 5, pp. 325-330, 2009.
[23] V. Lora, P. Gisondi, A. Calza, M. Zanoni, and G. Girolomoni, "Efficacy of a single educative intervention in patients with chronic plaque psoriasis," Dermatology, vol. 219, no. 4, pp. 316-321, 2009.

[24] J. de Korte, J. Van Onselen, S. Kownacki, M. A. G. Sprangers, and J. D. Bos, "Quality of care in patients with psoriasis: an initial clinical study of an international disease management programme," Journal of the European Academy of Dermatology and Venereology, vol. 19, no. 1, pp. 35-41, 2005.

[25] A. Wahl, B. R. Hanestad, I. Wiklund, and T. Moum, "Coping and quality of life in patients with psoriasis," Quality of Life Research, vol. 8, no. 5, pp. 427-433, 1999.

[26] H. L. Richards, D. G. Fortune, A. Weidmann, S. K. T. Sweeney, and C. E. M. Griffiths, "A cognitive-behavorial symptom management programme as an adjunct in psoriasis terapy," British Journal of Dermatology, vol. 146, pp. 458-465, 2002.

[27] A. Bessell and T. P. Moss, "Evaluating the effectiveness of psychosocial interventions for individuals with visible differences: a systematic review of the empirical literature," Body Image, vol. 4, no. 3, pp. 227-238, 2007.

[28] S. E. Thorne, S. R. Harris, K. Mahoney, A. Con, and L. McGuinness, "The context of health care communication in chronic illness," Patient Education and Counseling, vol. 54, no. 3, pp. 299-306, 2004.

[29] L. K. Bartholomew, G. S. Parcel, G. Kok, and N. H. Gottlieb, "Intervention mapping step 1: needs assesments," in Planning Health Promotion Programs: An Intervention Mapping Approach, pp. 193-250, Jossey-Bass, San Francisco, Calif, USA, 2006.

[30] R. Whittemore and K. Knafl, "The integrative review: updated methodology," Journal of Advanced Nursing, vol. 52, no. 5, pp. 546-553, 2005.

[31] R. Whittemore, "Combining evidence in nursing research: methods and implications," Nursing Research, vol. 54, no. 1, pp. 56-62, 2005.

[32] D. F. Polit and C. T. Beck, Essentials of Nursing Research: Appraising Evidence for Nursing Practice, Wolters Kluwer Health/Lippincott Williams \& Wilkins, Philadelphia, Pa, USA, 2010.

[33] C. Forsberg and Y. Wengström, Att Göra Systematiska Litteraturstudier, Författarna och bokförlaget Natur och kultur, Stokholm, Sweden, 2008.

[34] D. Moher, A. Liberati, and J. Tetzlaff, "Preferred reporting items for systematic reviews and meta-analyses: the PRISMA statement," Annals of Internal Medicine, vol. 151, pp. 264-269, 2009.

[35] S. Thorne, "Making sense of data," in Interpretative Description, pp. 141-153, Left Coast Press, Walnut Creek, Calif, USA, 2008.

[36] M. Risjord, Nursing Knowledge: Science, Practice and Philosophy, Whiley-Blackwell, 2010.

[37] A. Wahl, J. H. Loge, I. Wiklund, and B. R. Hanestad, "The burden of psoriasis: a study concerning health-related quality of life among Norwegian adult patients with psoriasis compared with general population norms," Journal of the American Academy of Dermatology, vol. 43, no. 5, pp. 803-808, 2000.

[38] A. K. Wahl, E. Gjengedal, and R. Hanestad, "The bodily suffering of living with severe psoriasis: in-depth interviews with 22 hospitalized patients with psoriasis," Qualitative Health Research, vol. 12, no. 2, pp. 250-261, 2002.

[39] D. G. Fortune, H. L. Richards, C. J. Main, and C. E. M. Griffiths, "Patients' strategies for coping with psoriasis," 
Clinical and Experimental Dermatology, vol. 27, no. 3, pp. 177184, 2002.

[40] D. G. Fortune, H. L. Richards, C. E. M. Griffiths, and C. J. Main, "Psychological stress, distress and disability in patients with psoriasis: consensus and variation in the contribution of illness perceptions, coping and alexithymia," British Journal of Clinical Psychology, vol. 41, no. 2, pp. 157-174, 2002.

[41] H. L. Richards, D. G. Fortune, S. L. P. Chong et al., "Divergent beliefs about psoriasis are associated with increased psychological distress," Journal of Investigative Dermatology, vol. 123, no. 1, pp. 49-56, 2004.

[42] B. Jankowiak, E. Krajewska-Kulak, K. Van Damme-Ostapowicz et al., "The need for health education among patients with psoriasis," Dermatology Nursing, vol. 16, no. 5, pp. 439444, 2004.

[43] C. J. O'Leary, D. Creamer, E. Higgins, and J. Weinman, "Perceived stress, stress attributions and psychological distress in psoriasis," Journal of Psychosomatic Research, vol. 57, no. 5, pp. $465-471,2004$.

[44] D. G. Fortune, H. L. Richards, B. Kirby, K. McElhone, C. J. Main, and C. E. M. Griffiths, "Successful treatment of psoriasis improves psoriasis-specific but not more general aspects of patients' well-being," British Journal of Dermatology, vol. 151, no. 6, pp. 1219-1226, 2004.

[45] A. W. M. Evers, Y. Lu, P. Duller, P. G. M. Van Der Valk, F. W. Kraaimaat, and P. C. M. Van De Kerkhoft, "Common burden of chronic skin diseases? Contributors to psychological distress in adults with psoriasis and atopic dermatitis," British Journal of Dermatology, vol. 152, no. 6, pp. 1275-1281, 2005.

[46] A. K. Wahl, C. Mørk, B. R. Hanestad, and S. Helland, "Coping with exacerbation in psoriasis and eczema prior to admission in a dermatological ward," European Journal of Dermatology, vol. 16 , no. 3, pp. 271-275, 2006.

[47] J. Unaeze, T. Nijsten, A. Murphy, C. Ravichandran, and R. S. Stern, "Impact of psoriasis on health-related quality of life decreases over time: an 11-year prospective study," Journal of Investigative Dermatology, vol. 126, no. 7, pp. 1480-1489, 2006.

[48] L. Dubertret, U. Mrowietz, A. Ranki et al., "European patient perspectives on the impact of psoriasis: the EUROPSO patient membership survey," British Journal of Dermatology, vol. 155, no. 4, pp. 729-736, 2006.

[49] M. Uttjek, L. Nygren, B. Stenberg, and M. Dufåker, "Marked by visibility of psoriasis in everyday life," Qualitative Health Research, vol. 17, no. 3, pp. 364-372, 2007.

[50] A. M. Eghlileb, E. E. G. Davies, and A. Y. Finlay, "Psoriasis has a major secondary impact on the lives of family members and partners," British Journal of Dermatology, vol. 156, no. 6, pp. 1245-1250, 2007.

[51] T. Watson and G. P. de Bruin, "Impact of cutaneous disease on the self-concept: an existential-phenomenological study of men and women with psoriasis," Dermatology Nursing, vol. 19, no. 4, pp. 351-364, 2007.

[52] B. Amatya and K. Nordlind, "Focus groups in Swedish psoriatic patients with pruritus," Journal of Dermatology, vol. 35, no. 1, pp. 1-5, 2008.

[53] P. Magin, J. Adams, G. Heading, D. Pond, and W. Smith, "The psychological sequelae of psoriasis: results of a qualitative study," Psychology, Health and Medicine, vol. 14, no. 2, pp. 150161, 2009.

[54] D. Globe, M. S. Bayliss, and D. J. Harrison, "The impact of itch symptoms in psoriasis: results from physician interviews and patient focus groups," Health and Quality of Life Outcomes, vol. 7, article 62, 2009.
[55] T. M. Ljosaa, T. Rustoen, C. Mørk et al., "Skin pain and discomfort in psoriasis: an exploratory study of symptom prevalence and characteristics," Acta Dermato-Venereologica, vol. 90, no. 1, pp. 39-45, 2010.

[56] D. G. Fortune, H. L. Richards, and C. E. M. Griffiths, "Psychologic factors in psoriasis: consequences, mechanisms, and interventions," Dermatologic Clinics, vol. 23, no. 4, pp. 681-694, 2005.

[57] B. G. Link and J. C. Phelan, "Conceptualizing stigma," Annual Review of Sociology, vol. 27, pp. 363-385, 2001.

[58] K. J. Petrie and J. Weinman, "Patients' perceptions of their illness," Current Directions in Psychological Science, vol. 21, pp. 60-65, 2012.

[59] B. Jankowiak, E. Krajewska-Kulak, A. Baranowska et al., "The importance of the health education in life quality improvement in patients with psoriasis," Roczniki Akademii Medycznej w Białymstoku, vol. 50, supplement 1, pp. 145-147, 2005.

[60] S. Thorne, "Communication in chronic care: confronting the evidence challenge in an era of system reform," Journal of Clinical Nursing, vol. 17, no. 11, pp. 294-297, 2008.

[61] S. Thorne, "Chronic disease management: what is the concept?" Canadian Journal of Nursing Research, vol. 40, no. 3, pp. 7-14, 2008.

[62] D. De Silva, "Evidence: helping people help themselves: a review of the evience conserning whether it is worth to support self-management," 2011.

[63] L. K. Bartholomew, Planning Health Promotion Programs: An Intervention Mapping Approach, Jossey-Bass, San Francisco, Califm USA, 2006.

[64] R. Kennedy and J. Phillips, "Social return on investment (SROI): a case study with an expert patient programme," SelfCare, vol. 2, no. 1, pp. 10-20, 2011.

[65] "Chronic Disease Self-Management Program," Patient Education, Department of Medicine, Stanford University School of Medicine, 2012.

[66] T. Henseler and E. Christophers, "Psoriasis of early and late onset: characterization of two types of psoriasis vulgaris," Journal of the American Academy of Dermatology, vol. 13, no. 3, pp. 450-456, 1985.

[67] G. Scambler and S. J. Scambler, New Directions in the Sociology of Chronic and Disabling Conditions: Assaults on the Lifeworld, Palgrave Macmillan, New York, NY, USA, 2010.

[68] C. S. Koblenzer, "The emotional impact of chronic and disabling skin disease: a psychoanalytic perspective," Dermatologic Clinics, vol. 23, no. 4, pp. 619-627, 2005.

[69] F. E. Fox, N. Rumsey, and M. Morris, "Ur skin is the thing that everyone sees and you cant change it!: exploring the appearance-related concerns of young people with psoriasis," Developmental Neurorehabilitation, vol. 10, pp. 133-141, 2007.

[70] S. Booker, M. Morris, and A. Johnson, "Empowered to change: evidence from a qualitative exploration of a userinformed psycho-educational programme for people with type 1 diabetes," Chronic Illness, vol. 4, no. 1, pp. 41-53, 2008.

[71] M. Kirkevold, "Integrative nursing research—an important strategy to further the development of nursing science and nursing practice," Journal of Advanced Nursing, vol. 25, no. 5, pp. 977-984, 1997. 


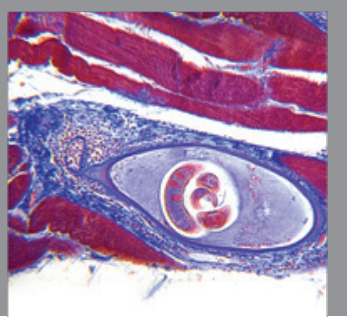

Gastroenterology

Research and Practice


International Journal of Inflammation
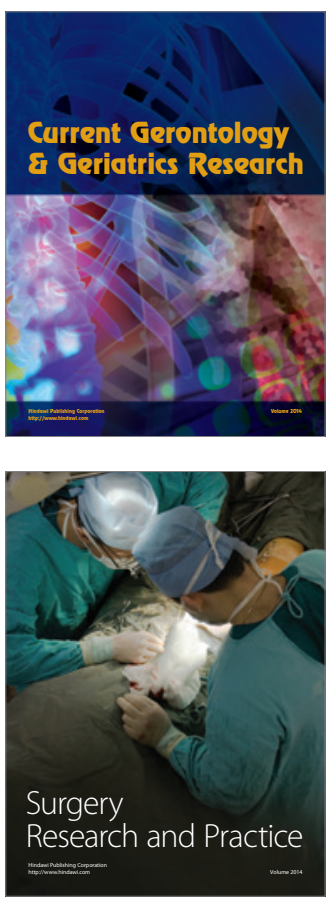


Submit your manuscripts at

http://www.hindawi.com
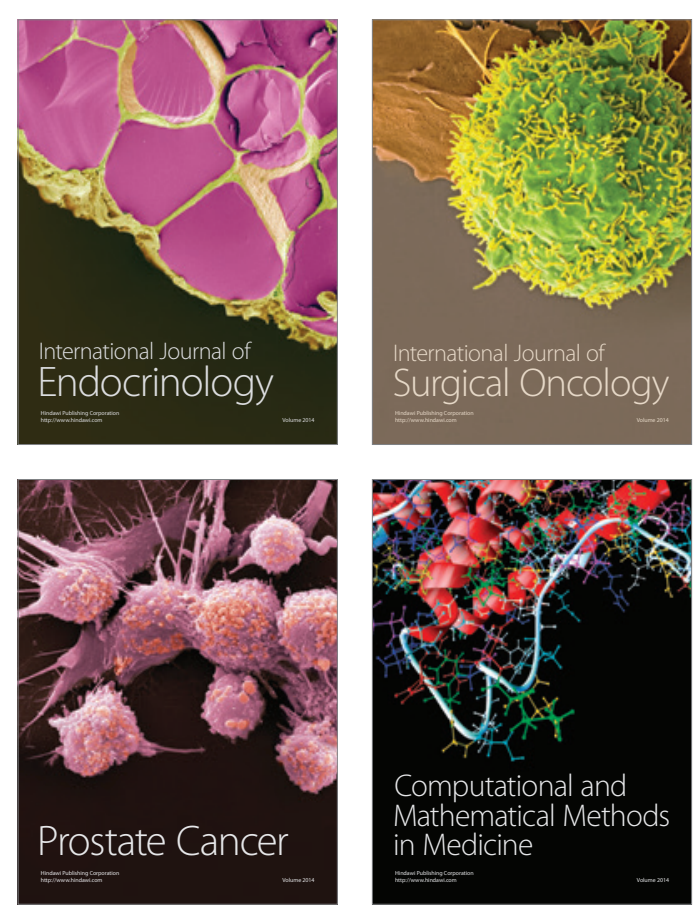
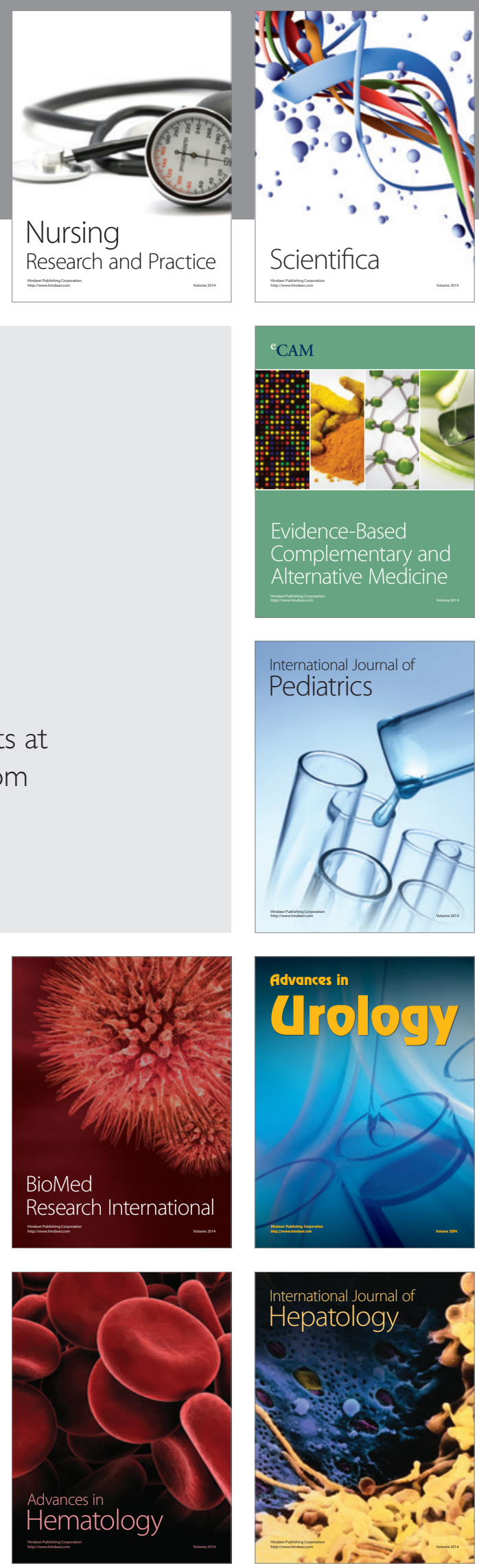